\title{
Reference Pricing and Price Negotiations for Innovative New Drugs
}

\author{
Viable Policies in the Long Term?
}

\author{
Afschin Gandjour
}

Published online: 6 November 2012

(c) Springer International Publishing Switzerland 2012

Given the high costs of innovative new drugs, most countries have introduced policies for price control. Two policies have become popular in recent years: international reference pricing (IRP) and value-based pricing (VBP). Another policy that was recently introduced in Germany consists of price negotiations between payers and manufacturers followed by IRP and VBP in case of no agreement. ${ }^{1}$ These policies are usually preceded by an assessment of medical benefits against current standards (e.g. in France [3] and Germany [1]) and thus are only applied in case evidence for medical benefits exists.

IRP is "the practice of using the price(s) of a medicine in one or several countries in order to derive a benchmark or reference price for the purposes of setting or negotiating the price of the product in a given country" [4]. In some countries, the referencing pricing system is applied rigidly, while in other countries, it is simply one of many elements of information used to inform the pricing decision [4]. By taking comparison prices from other countries, the regulation of drug prices in one country can directly affect prices in another. A recent review [5] showed that among the 27 European Union (EU) Member States only four countries did not use IRP in 2010 (Denmark, Germany, Sweden and the UK). Among the EU countries using IRP, the most commonly used method was to take the average of the country basket [5]. Bulgaria, Greece and Norway took the average of the three lowest countries [5].

\footnotetext{
A. Gandjour $(\bowtie)$

Frankfurt School of Finance and Management,

Sonnemannstr. 9-11, 60314 Frankfurt am Main, Germany

e-mail: a.gandjour@fs.de

A. Gandjour

Department of Public Health, Faculty of Medicine,

Heinrich-Heine-University, Düsseldorf, Germany
}

In contrast, VBP sets drug prices based on the value they provide. The fundamental principle of the VBP approach is that the costs of drugs (including savings from avoiding morbidity) should not exceed their health benefits. VBP thus is also applied in pay-for-performance agreements when performance is measured based on value. VBP is based on an implicit or explicit decision rule, which compares the incremental cost-effectiveness ratio of a drug with a threshold willingness to pay, e.g. $£ 20,000$ to $£ 30,000$ per QALY gained in England and Wales [6]. This threshold willingness to pay is sensitive to ethical values and may increase with unmet need (e.g. in England and Wales for patients with a short life expectancy [7]).

The purpose of this paper is to show that IRP (possibly followed by price negotiations) or price negotiations followed by IRP and VBP in case of no agreement are not sustainable in the long run and will lead to VBP. As a word of caution, the argument is only made with respect to innovative new drugs and not me-too drugs with no

\footnotetext{
${ }^{1}$ In Germany, the new legislation regulating the reimbursement of drugs within the statutory healthcare system (Arzneimittelmarktneuordnungsgesetz [AMNOG]) considers as a first step early benefit assessment of new drugs [1]. This is followed by internal reference pricing when there is no sufficient evidence of added clinical benefits compared with existing standard treatment [1]. If benefits are confirmed, manufacturers and representatives of the statutory health insurance have half a year to negotiate an appropriate reimbursement price [2]. This process is informed by data of manufacturers on any discounts given in other European countries [2]. The first price negotiation, which took place for the drug ticagrelor, suggests that IRP will play an important role in future price negotiations. Yet, at this point one cannot assume that IRP will always come into play. If drug makers and health insurers cannot agree on the price, a final decision on the reimbursement price will be made by an arbitration body [2]. To this end, the arbitration body will use IRP [2]. If one of the parties involved wishes so, a formal evaluation of costs and benefits of the product in question will be initiated [2].
} 
additional benefit. For the latter, reference pricing may well have a role in expenditure control.

\section{Rationale}

Consider a set of countries where each country uses one of three pricing strategies: (1) VBP, (2) IRP possibly followed by price negotiations with the manufacturer, or (3) price negotiations followed by IRP and VBP in case of no agreement. That is, there is no country without a price policy. This corresponds to the situation of the EU. What is the likely outcome of this scenario? First, consider that the price of an IRP country can be calculated as follows:

price $_{\text {IRP }}=\frac{\sum_{j=1}^{m} \sum_{i=1}^{n} i \times \text { price }_{j}}{m}$

where $i$ denotes a reference country using IRP, $n$ is the total number of reference countries using IRP, $j$ is a reference country adopting VBP, and $m$ is the total number of reference countries adopting VBP. The equation is based on the intuition that for a given IRP country the boundaries of the price are strictly determined by reference countries adopting VBP and not by reference countries using IRP. The reason is that reference countries using IRP reference to VBP countries too. Thus, the number of countries referencing to a VBP country serves as weight for the price in that VBP country. Accordingly, the price in the IRP country in question is calculated as a weighted average of prices in VBP countries.

While the equation assumes that each IRP country receives the same weight, it is easy to avoid this assumption, by introducing differential weights. The equation applies regardless of whether the average of the country basket, the average of the three lowest countries or the lowest price per basket is taken. Note that if the average of the three lowest countries is taken, $m$ in Eq. 1 may be larger or smaller than three as these three countries may refer to more or less than three VBP countries. On the other hand, $n$ cannot be larger than three as each VBP country has no more than three countries referring to it.

If IRP countries determine prices based on existing prices in VBP countries and not based on expected or predicted prices, the order by which a manufacturer enters different countries becomes important. Eq. 1 implies that manufacturers will first launch the drug in a VBP country with the highest expected price as manufacturers cannot obtain a higher price by launching first in an IRP country. The underlying reason is that the highest achievable price in IRP countries is determined by the highest price in VBP countries. In other words, IRP countries cannot take a higher price than their reference group. Next, manufacturers may launch in an IRP country if its expected price is higher than that of the second-highest VBP country. The VBP country with the lowest expected price will receive the drug last.

For countries where price negotiations with the manufacturer are followed by IRP and VBP in case of no agreement, VBP will automatically follow. To explain, let's assume first that price negotiations are only followed by IRP in case of no agreement and that during the initial negotiation the payer insists on a lower price than expected by IRP. In this case, the manufacturer will avoid agreement and wait for IRP. Hence, the manufacturer's reservation price will be the price based on IRP. On the other hand, if the manufacturer insists on a higher price during the negotiation than expected by IRP, then the payer will avoid agreement and wait for IRP. If both players anticipate this outcome, they will agree on the price set by IRP. Now, assume that price negotiations are first followed by IRP and then by VBP in case IRP is rejected by one of the negotiating parties (this corresponds to the situation in Germany). In this case, the payer has no incentive to accept a price above the value-based price and the manufacturer has no incentive to accept a price below. Again, players will anticipate this outcome and settle on the price based on VBP.

\section{Discussion}

This paper shows that IRP or price negotiations followed by IRP or VBP in case of no agreement will lead to VBP. In IRP countries prices are thus determined by the decision rules and ethical values in VBP countries. Given that each country has its own ethical values and willingness to pay for a health gain, countries using IRP will have difficulties justifying the unrestricted transfer of implicit or explicit decision rules (such as a $£ 30,000$-per-QALY-gained rule) and ethical values from VBP countries. This holds in particular when the number of VBP countries is small (such as in the EU), so that the price in country A can be clearly traced to decision rules and ethical values in countries $\mathrm{B}$ and C. Yet, country A may be more sensitive than countries $\mathrm{B}$ and $\mathrm{C}$ in putting an explicit dollar value on a person's life, in considering productivity gains as part of the value equation, or in rationing access to pharmaceuticals. Historical misuse of valuing people's lives, such as during the Nazi era, may influence the feelings of politicians and citizens in some countries more than others [8]. Hence, each country needs to develop its own VBP rule, based on its ethical values and history. Note that the existence of confidential rebates for drugs in some countries does not alter this conclusion. That is, prices in IRP countries are still calculated based on the weighted-average price in VBP countries. The only difference confidential rebates make is 
that the weighted-average price in a given country may be reduced below that of any VBP country.

The practice of simply transferring prices from VBP countries is further limited by the fact that drug prices determined based on VBP depend on the type and size of the relevant population. When a drug is only reimbursed for a high-risk population, prices tend to be higher than when it is reimbursed for the whole population. Similarly, when a drug is reimbursed only for the population with an actual health gain (e.g. in a pay-for-performance risksharing scheme), prices will also be higher than when it is reimbursed for the whole population. This raises the question of whether country A, which relies on IRP, reimburses the drug for a population with a similar risk as countries $\mathrm{B}$ and $\mathrm{C}$ do. If not, this would underline the need for country A to conduct an independent VBP assessment.

The incentive for manufacturers to market their products first in countries where they are allowed to set a higher price, given that this will influence the price in reference countries, is well described in the literature $[9,10]$. What this paper adds is that the first and last country to enter will use VBP because VBP countries set the boundaries of the price in IRP countries. It also has been noted [11] that in extreme cases manufacturers may not launch a drug at all in a particular country when a low price would reduce prices in other countries through IRP. Hence, IRP may prohibit the access of patients to new drugs in low-income countries. The model described in Eq. 1 suggests that manufacturers will be particularly hesitant to enter the VBP country with the lowest expected price as this country serves as the bottom anchoring point for reference prices.

One may postulate that over time IRP countries will learn from each other and expect similar discounts/rebates from manufacturers. Still, some argue that companies may insist on lower discounts/higher prices in lower-price countries than they would otherwise, if the impact of IRP on prices elsewhere was not a concern. As a result, because of IRP, lower-price countries may actually pay more relative to income than higher-price countries [11]. Again, this may limit access to new drugs in low-income countries and underlines the need for VBP in each country from a global viewpoint (i.e. pricing according to the ability to pay) [11]. Finally, IRP may be limited by exchange rate volatility, which may have a significant impact on pharmaceutical prices and price revisions [12].

A similar prediction that "external reference pricing will soon reach the end of its useful life cycle" was recently made by Seiter [13] but based on another premise. He argued that "when almost all countries reference each other and prices converge, the differences between countries diminish" [13]. Here it is argued that it is not the convergence of prices that will lead to an end of IRP but the decision rules and ethical values in countries not using reference pricing.

Note that countries in which IRP is followed by price negotiations may also use criteria other than reference prices, e.g. R\&D costs [5]. IRP countries using other criteria may thus set prices outside the range of VBP countries. Still, the majority of IRP countries in the EU use external prices as the main criterion [5]. Similarly, countries relying on price negotiations followed by IRP or VBP in case of no agreement may also use additional criteria. Moreover, countries may use volume agreements in order to limit the budget impact [14]. Still, regardless of whether or not other criteria for spending control exist, the conclusion that IRP and price negotiations are not sustainable in the long run still holds because they will lead to VBP (with or without additional criteria).

VBP may still be inhibited by high procedural costs compared with IRP [15]. Still, in some jurisdictions costs of VBP may be rather low (e.g. in Scotland) [15]. In any case, countries may look for ways to reduce the information needed to determine drug prices [16].

The arguments provided in this paper concerning the sustainability of IRP and price negotiations also apply to health interventions such as medical equipment when there is a set of countries using the three pricing policies mentioned.

Acknowledgments There are no potential conflicts of interest. The author would like to thank two anonymous reviewers and the Editor for their very helpful comments on an earlier draft.

\section{References}

1. German Social Security Code (SGB), book V, § 35a; 2012.

2. German Social Security Code (SGB), book V, § 130b; 2012.

3. Chicoye A, Chhabra A. France: pharmaceuticals. In: ISPOR Global Health Care Systems Road Map. ISPOR. 2009. http:// www.ispor.org/htaroadmaps/France.asp\#4. Accessed 4 Oct 2012.

4. European Federation of Pharmaceutical Industries and Associations. Glossary of terms. 2012. http://www.efpia-annualreview.eu/ index.php?page=glossary-of-terms. Accessed 4 Oct 2012.

5. Leopold C, Vogler S, Mantel-Teeuwisse AK, de Joncheere K, Leufkens HG, Laing R. Differences in external price referencing in Europe: a descriptive overview. Health Policy. 2012;104(1): $50-60$.

6. National Institute for Health and Clinical Excellence. Incorporating health economics in guidelines and assessing resource impact. In: The guidelines manual. London: NICE; 2007. http:// www.nice.org.uk/niceMedia/pdf/GuidelinesManualChapter8.pdf. Accessed 4 Oct 2012.

7. National Institute for Health and Clinical Excellence. Appraising life-extending, end of life treatments. London: NICE; 2009. http:// www.nice.org.uk/media/88A/F2/SupplementaryAdviceTACEoL. pdf. Accessed 4 Oct 2012.

8. Gandjour A, Lauterbach KW. International comparison of output and productivity in health economics research (in German). Inform Biom Epidemiol Med Biol. 2003;34(2):88-95. 
9. Kyle M. Pharmaceutical price controls and entry strategies. Rev Econ Stat. 2007;89:88-99.

10. Jarosławski S, Toumi M. Market access agreements for pharmaceuticals in Europe: diversity of approaches and underlying concepts. BMC Health Serv Res. 2011;11:259.

11. Garau M, Towse A, Danzon P. Pharmaceutical pricing in Europe: is differential pricing a win-win solution? Occasional paper no.11/01. London: Office of Health Economics; 2011.

12. Kanavos P, Nicod E, Espin J, et al. Short- and long-term effects of value-based pricing vs. external price referencing. Brussels: European Commission; 2010. http://ec.europa.eu/enterprise/ sectors/healthcare/files/docs/valuebased_pharmapricing_012010_ en.pdf. Accessed 4 Oct 2012

13. Seiter A. A practical approach to pharmaceutical policy. Washington, DC: The World Bank; 2010.
14. Adamski J, Godman B, Ofierska-Sujkowska G, Osińska B, Herholz H, Wendykowska K, Laius O, Jan S, Sermet C, Zara C, Kalaba M, Gustafsson R, Garuolienè K, Haycox A, Garattini S, Gustafsson LL. Risk sharing arrangements for pharmaceuticals: potential considerations and recommendations for European payers. BMC Health Serv Res. 2010;7(10):153.

15. Drummond M, Jönsson B, Rutten F, Stargardt T. Reimbursement of pharmaceuticals: reference pricing versus health technology assessment. Eur J Health Econ. 2011;12(3):263-71.

16. Gandjour A, Gafni A. The German method for setting ceiling prices for drugs: in some cases less data are required. Expert Rev Pharmacoecon Outcomes Res. 2011;11(4):403-9. 